\title{
Role of Acoustic Radar in Earthquake Precursor Detection
}

\author{
${ }^{1}$ Rinki Goel, ${ }^{2}$ Harshdeep Singh Batra and ${ }^{3}$ H. N. Dutta \\ Silver Line Prestige School, Ghaziabad, India \\ ${ }^{1}$ Email: rinkigoel14@gmail.com
}

\begin{abstract}
In the field of earthquake precursors, most of the researchers are now realizing that the feeble amount of energy /mass /momentum etc. released prior to main rapture by a major earthquake, should be good enough to cause large amount of changes in the atmospheric parameters which can be easily detected. The above requirement of monitoring can only be fulfilled by techniques like acoustic radar /Lidar that monitor atmosphere in pictorial form on 24-hour basis or use satellitebased monitoring. The data must be processed within minimum possible time and the conclusions must be drawn in order to issue the most wanted warning of an impending earthquake. It is important to note that in India, a major earthquake with magnitude of $>8.0$ is overdue and we need to address this issue of precursor detection on priority.
\end{abstract}

We at the Silver Line Prestige School are working on acoustic radar technology which maps the dynamics of the lowest $1 \mathrm{~km}$ of the atmosphere as it presents data in the photographic form. The problems associated in utilizing this technique are presented in this paper.

Index Terms-Acoustic radar, earthquake precursor, facsimile charts, pattern recognition

\section{INTRODUCTION}

An earthquake is the most devastating natural phenomenon where energy release per second is the highest and by the time, Earth based instruments detects its arrival, destruction and associated death, injuries and trauma stand as a challenge before mankind [1]. India is facing a serious threat from a major earthquake striking somewhere over northern India [2-3]. It is a high time that we understand the precursory processes and the potential technologies for the detection of precursory signatures associated with an impending earthquake [4-8]. A timely warning will not be able to save destruction but it will save untimely deaths, injuries and people trapped under debris. It will cut down the cost of handling medical emergency and disposal of dead bodies. A timely warning will also help in shutting down major nuclear installations, handle electricity distribution, enhance vigil on dams and reduce speed of entire transport system in the nation.

Fortunately, India holds an international patent in detecting precursor of an earthquake using an acoustic radar [9] and to create this facility, a java based acoustic radar has been designed, developed and installed at the Roorkee Engineering and Management Technology Institute, Shamli, India so as to provide an easy access for professionals working in the field of earthquake precursor in India/ abroad
[10]. However, it is important to understand that just by establishing acoustic radar/ radars, it will not solve the problem of detecting precursor of an earthquake; we need to address many other related issues, which are discussed in this paper.

Before realizing the problems, let us understand the acoustic radar technology in terms of its detection capability and what exactly it will detect so as to be sure about its capability as a precursor detection of a major earthquake.

\section{ACOUSTIC RADAR TECHNOLOGY}

In acoustic radar, an antenna mounted on the surface of Earth, transmits a powerful pulse of sound vertically up into the air. The amplitude of the transmitted pulse propagating in the vertical direction gets scattered by the thermal perturbations or inhomogeinites present in the atmosphere. The backscattered component of the sound energy is picked up by the receiving antenna in a monostatic mode. For each pulse, it takes 6 seconds to probe $1 \mathrm{~km}$ of the lowest atmosphere $(3$ seconds for sound to go up to a height of $1 \mathrm{~km}$ and 3 seconds to return). The received sound energy is plotted as as a line of 400 dots in a period of 6 seconds. The process of transmission, reception and data plotting is handled by a dedicated software. Fig. 1 shows photograph of acoustic radar antenna installed at REMTech, Shamli. Fig. 1 shows a hexagonal shield mounted on a raised platform that surrounds a 4 feet parabolic dish, working as a transmitting as well receiving antenna. This shield houses antenna in a relatively noise free environment so as to increases $\mathrm{S} / \mathrm{N}$ ratio of the received signals. The $\mathrm{S} / \mathrm{N}$ ratio is enhanced by pasting $100 \mathrm{~mm}$ thick ms foam of 32 density. Shield also helps in cutting down the horizontal propagation of transmitted energy so as to cut down the reflection from nearby tall structures. At the same time, shield prevents development of reverberations within the structure.

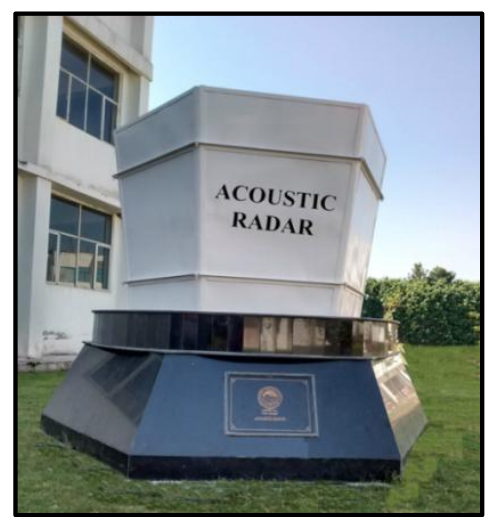

Fig. 1. Acoustic radar antenna houses 4 feet parabolic dish 466 
surrounded by hexagonal shield. The height of shield is $1.6764 \mathrm{~m}$.

Fig. 2. shows isometric view of the acoustic radar shield. In our case, it is a metallic shield mounted on a raised platform specifically developed to give an aesthetic look.

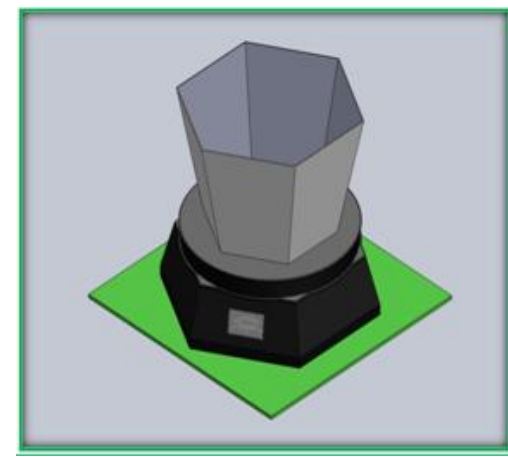

Fig. 2 Isometric view of the shield.

Fig. 3 shows the pictorial data output from an acoustic radar. Basically, it is a line by line scan in which each pixel is given a shade / colour code depending upon the signal strength. The pattern of the received signal can be inferred after every 15 to 30 minutes and it varies with the weather conditions. Fig. 3 has captured thermal convection during the daytime. This picture is formed by the heating of the surface of Earth by the solar energy. The falling energy from the Sun is roughly the same over a wide area but due to differences in the albedo and specific heat capacities at various places (like, road, building, park, drainage, trees etc.), thermal convection is recorded as thermal plumes [1112]. Thermal plumes show well mixed atmosphere.

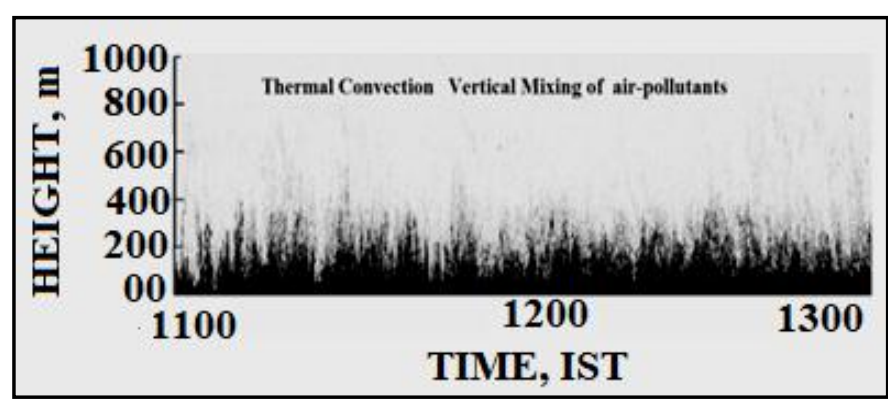

Fig. 3 Thermal convection is seen during the daytime and remains suppressed during peak winter season.

Fig. 4 is a record of fog over the Indian Antarctic station, Maitri. Sitting on the surface of Earth, it is impossible to judge the vertical extent of the fog. On the acoustic radar facsimile record, it is seen clearly that fog is not uniform in terms of its density and its height is touching about $800 \mathrm{~m}$ in thickness. This figure shows capability of acoustic radar to detect minute changes in temperature associated with humid air or tinny water droplets.

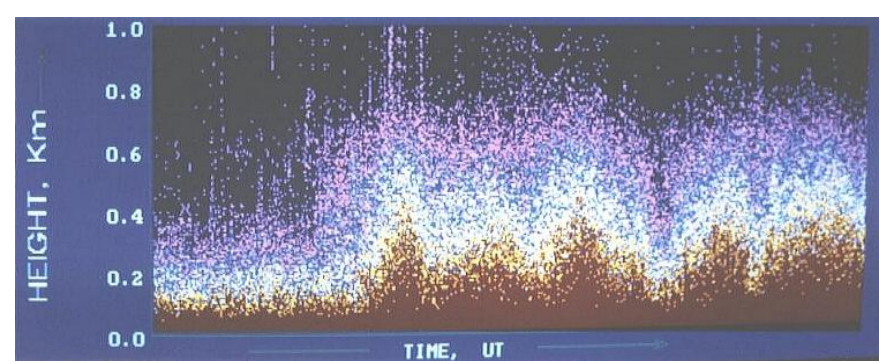

Fig. 4 Facsimile chart of fog

The site at Shamli is surrounded by cultivated fields but it is seen that the site experiences whirlwind incidences. In the whirlwind, a vortex of wind forms due to instabilities and turbulence created by heating and flow gradients. In Fig5., whirlwind started at 1220 IST and continued up to 1310 IST. However, it is important to note that although acoustic radar detects almost all weather phenomena but like an EM radar, it doesn't chase a target. It records it's footprints as it passes over the antenna. In the case, development takes place over the site or in the adjoining area, the signature increases its height with time and in this case, its vertical speed has come to be $1.46 \mathrm{~m} / \mathrm{s}$. In the case, whirlwind passes over the site, its signature decreases in height with time.

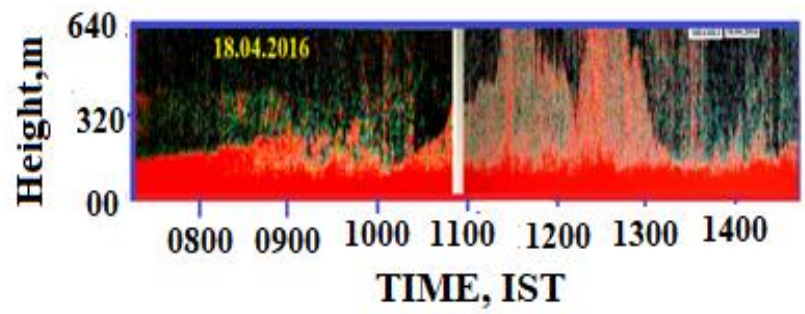

Fig. 5 Whirlwind event recorded over REMTech, Shamli

Fig. 6 is a unique facsimile chart which shows sudden enhancement of thermal structure in the morning at 0500 IST, this can only be caused by a cold cloud moving in the upper regions, thereby creating sudden vertical movement. At 0500 IST, we can't expect any source of sudden heat on the ground.

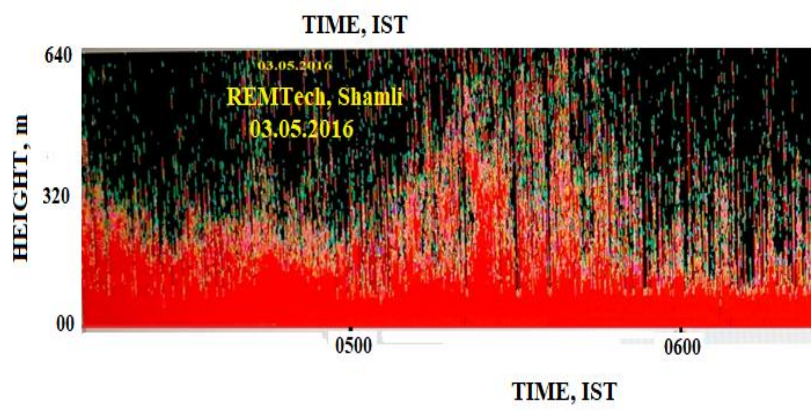

Fig. 6. Depiction of passage of cloud in the upper regions 
Fig. 7 shows movement of surface based inversion formed at night under the influence of solar heating, leading to the formation of gravity waves and the rising layer. Acoustic radar has the capacity to record changes $\sim$ of 5 minutes or so and height differences of about $20 \mathrm{~m}$ or so. In this case, gravity wave period is about 11 minutes. It is important to note that the photographs depicted in this paper, are highly compressed, in actual data, we can differentiate at a scale of seconds.

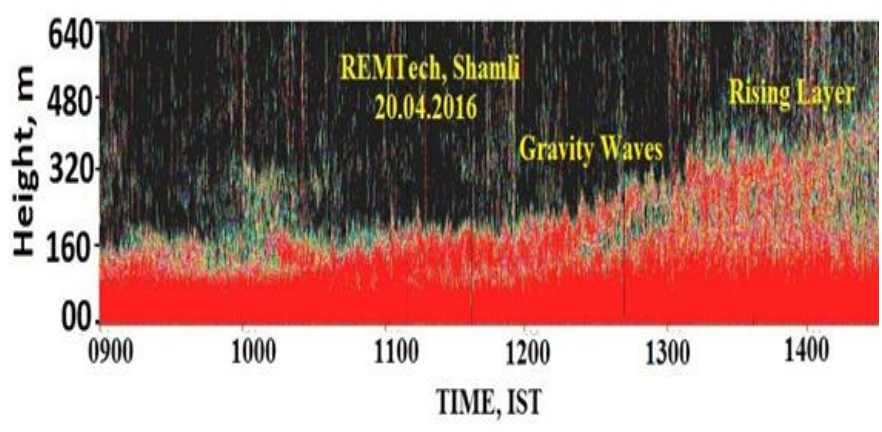

Fig. 7 Facsimile chart depicting dynamics of atmosphere depicting several atmospheric phenomena

All the facsimile charts of acoustic radar depict its capability to record minute changes in the atmosphere, these are normally caused or are formed by lithosphereatmosphere coupling where heat energy transfer causes thermal convection, surface based and elevated layers, wind shear etc.

Our aim is to see, if this equipment can be used to detect changes in the atmosphere caused by various phenomena before the rapture of a major earthquake.

\section{EARTH-ATMOSPHERE COUPLING}

In view of earthquake precursor detection, it is important to realize that nature has created mother Earth, which has a mass of $5.972 \times 10^{24} \mathrm{~kg}$. Compared to this, mean mass of air on Earth is $5.1480 \times 10^{18} \mathrm{~kg}$. This means Earth is enclosed in a shell of air, which is million times lighter. Moreover, Earth's surface has specific heat $\left(\sim 0.20 \quad \mathrm{Cal} / \mathrm{gram}^{\circ} \mathrm{C}\right)$ comparable to air; this means both the surface of Earth and air are thermally linked. Grant et al.[5] have clearly discussed role of chemical changes prior to earthquake and induction of positive air ions into the lower atmosphere. Air laden with positive ions leads to condensation of water droplets, causing haze and clouds. When positive air ions reach the Earth surface, the $h^{\circ}$ can pairwise recombine to form proxy bonds again. This is an exothermal reaction. It leads to vibrationally highly excited states, which de-excite by emitting infrared photons, leading to the creation of "thermal anomalies" captured in night-time infrared satellite images of the areas around future epicenters. The thermal anomaly close to the surface of earth, will certainly cause change in atmosphere and acoustic radar is the most promising technique to record such changes.

Vol. 3 (3), September 2019, www.ijirase.com
Ouzounov and Freund [13] have detected mid-infrared emission prior to strong earthquakes analyzed by remote sensing data, it means, there is an enhancement in the temperature over earthquake preparation zone. Mulargia et al. [6] have stressed that there are three phases involved in the journey of an earthquake. These phases are important to release heat energy, material in gas, liquid and solid phasesall leading to change in atmosphere. Anders et al. [7] have emphasized that micro-fracturing processes before a major earthquake strikes. These have high-aspect-ratio cracks in rock that result from application of differential stresses. In geologic settings, microfractures commonly form as Mode I (opening) fractures where the minimum principal stress exceeds the elastic tensile strength creating a narrow opening displacement; in isotropic rocks such fractures mark the plane perpendicular to the least compressive principal stress during fracture growth. These planar or curviplanar openings provide an opportunity for fluids and/or gases to enter the created cavity. Understanding of these microfractruing processes can lead to understand precursory phenomenon.

\section{PROBLEMS IN ACOUSTIC RADAR TECHNOLOGY}

Acoustic radar technology has been accepted as a promising technology to detect precursory changes / signals [14]. However, just by deploying acoustic radar will not solve the problem, we need to address the following:

1. Pattern recognition: In acoustic radar, data gets generated after every 6 seconds and we can safely presume, one hour data to be a pattern different from rest of the patterns. Therefore, the problem is that we need to develop an online pattern classification / recognition software that will sort out data into different bins, each being classified based on its time of occurrence, season, meteorological conditions and surface based seismic data sets. We need to identify all the signatures which can possibly be generated by nature, without the incidence of an earthquake, so that when we have an incidence related to earthquake, it gets identified automatically. Human intervention is impossible. To mitigate this problem, we need to install a number of acoustic radars in India and receive data at one place, where pattern recognition team develops the software. To start working on this problem, Deb et al. [15-16] have undertaken preliminary work that must be extended.

2. Networking and inter-comparison: Acoustic radar need to be installed in earthquake prone regions so that acoustic radar data is studied in relation to earthquake related parameters.

\section{CONCLUSION}

We have acoustic radar technology to serve in the field but we need to have collaboration with active groups having various earthquake measuring techniques so that its potential gets fully utilized in the interest of humanity. At the same time, professional working on pattern recognition must contact us urgently so that his extremely important work starts in the interest of humanity. 


\section{ACKNOWLEDGEMENT}

Authors are grateful to Shri Subhash Jain, Chairman and Dr Mala Kapoor-Director Principal, Silver Line Prestige School, Ghaziabad for supporting the work. Authors thankfully acknowledge guidance given by the organizers of the International Conference on Contemporary Engineering and Technology-2019 held at Inderprastha Engineering College, Sahibabad, Ghaziabad.

\section{REFERENCES}

[1] J. E. Daniell, A. M. Schaefer, and F. Wenzel, Losses Associated with Secondary Effects in Earthquakes. Frontiers in Built Environment, DOI: 10.3389/fbuil.2017.00030, June, 2017.

[2] News Nation ALERT! Devastating earthquake expected in North India, can claim several human lives, https://www.newsnation.in/offbeat/earthquake-tremors-north-indiaquake-seismologists-himalayas-cause-human-lives-richtermagnitude-article-221580.html, April, 2019.

[3] K. S. Jayaraman, Himalaya poised to rupture in mega earthquakes, Nature, India doi:10.1038/nindia.2019.25, February 2019.

[4] R. D. Crago, and Qualls, R.J., Use of land surface temperature to estimate surface energy fluxes: Contributions of Wilfried Brutsaert and collaborators, Water Resour. Res., Vol. 50, pp. 3396-3408, doi:10.1002/ 2013WR015223., April, 2014.

[5] R. A. Grant, T. Halliday, W. P. Balderer, F. Leuenberger, M. Newcomer, G. Cyr, and F. T. Freund, Ground Water Chemistry Changes before Major Earthquakes and Possible Effects on Animals, Int.J. Enviro. Res. Public Health, vol. 8 no. 6, pp. 19361956. doi: 10.3390/ijerph8061936, June, 2011.

[6] F. Mulargia, S. Castellaro, and M. Ciccotti, Earthquakes as three stage processes, Geophysical Journal International, vol. 158, no. 1, pp. 98-108, https://doi.org/10.1111/j.1365-246X.2004.02262.x, July, 2004,

[7] M. H. Anders, E. L. Stephen, and H. S. Christopher, Microfractures: A review Journal of Structural Geology, vol. 69, Part B, pp. 377-394. https://doi.org/10.1016/j.jsg.2014.05.011, December, 2014.

[8] H. N. Dutta, R. S. Dabas, Das, R. and K. Sharma, Ionospheric Perturbations over Delhi Caused by the December 26, 2004 SUMATRA Earthquake, International Journal of Remote Sensing, vol. 28, no. 13-14, pp. 3141-3151, July, 2007.

[9] B. S. Gera, V. K. Ojha, G. Singh, and H. N. Dutta, Method for the detection of earthquake precursors, WO2005096014A1 WIPO (PCT), ,https://patents.google.com/patent/WO2005096014A1/en, Pub. October, 2005.

[10] K. Vats, A. Kumar, B. K. Kushwaha, B. K. Tyagi, R. Chaudhary, S. Chauhan, R. Rani, N.C. Deb, S. Kumar, R. Gupta, and H. N. Dutta, 8th International Conference on Recent Advances in Civil Engineering, Architecture and Environmental Engineering for Sustainable Development-ISBN: 978-81-930585-7-2, pp 13-16, September, 2015.

[11] H. S. Somal, D. Singh, S. S. Dhillon, H S. Gurm, H. N. Dutta, and S.K. Sarkar, ,A study of thermal plumes, Indian J. Radio and Space Phys., vol. 10, pp. 137-143, 1981.

[12] J. Naithani, and H. N. Dutta, Boundary-Layer Meteorol., vol. 76, no. 1-2, pp 199-207, https://doi.org/10.1007/BF00710897, October, 1995.

Vol. 3 (3), September 2019, www.ijirase.com
[13] D. Ouzounov, and F. T. Freund, Mid-infrared emission prior to strong earthquakes analyzed by remote sensing data. Adv. Space Res., vol. 33, no. 3, pp. 268-273, January, 2004. https://doi.org/10.1016/S02731177(03)00486-1

[14] B. S. Gera, N. Gera, and H. N. Dutta, Unique atmospheric wave : precursor to the 26 January 2001 Bhuj, India earthquake, International Journal of Remote Sensing, vol. 32, no. 23, pp. 8881-8889. DOI:10.1080/01431161.2010.542208, December, 2011.

[15] N. C. Deb, S. Ray Kumar, and H. N. Dutta, SODAR Pattern Classification by Graph Matching,.., IEEE Geoscience \& Remote Sensing Letters, vol. 18 , no. 3 pp. 483-487. DOI: 10.1109/LGRS.2010.2088105, Novemebr, 2010.

[16] N. C. Deb, S. Pal, D. C. Patranabis, and H. N. Dutta, A Neurocomputing Model for SODAR Structure Classification, International Journal of Remote Sensing, vol. 31, no. 11, pp. 2995-3018, July 2010.

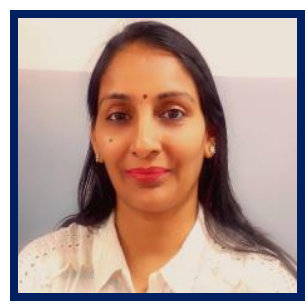

First Author Ms. Rinki Goel is the Head of the Computer Science Department, Silver Line Prestige School, Ghaziabad. She holds B.Sc., PGDIT, B.Ed., degrees to her credit and is working as a researcher in the field of earthquake precursor detection using acoustic radar technology. With her 15 years of teaching experience and innovations in developing various technological projects, Ms. Goel is a member of many international professional bodies, the prominent ones are: International Association of Engineers (IAE), Teaching \& Education Research Association (TERA), International Association of Science and Engineering for Development (IASED), International Association of Science and Engineering for Development (IASED). She has presented many research papers in international conferences and writes on Quora.com. . Her film entitled, "Benefits of cyclone for mankind" has won her first prize in the year 2017 from District Science and Technology Centre under U.P. Council for Science and Technology, Government of India, Lucknow.

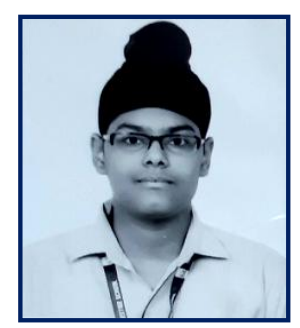

Second author Harshdeep Singh Batra is a bright student at the $11^{\text {th }}$ standard in the Silver Line Prestige School, Ghaziabad. He won the title of All Rounder in the year 2010 when he won awards in Calligraphy, Quiz, Art, Sports, Solo Dance etc. All these awards have transformed him as a meticulous planner, fine artist, sturdy player, lithe dancer, eloquent debater, topper in many subjects, who is a Marvelous Star in the School. At the same time, he has brought many laurels for the school. Some of his prizes are: DU Vinci Award at World Scholar Cup held at IPS, Indirapuram in April, 2015, he won Ist position in collaborative writing at Patna-World Scholar's Cup in 2015. Harshdeep is a fine writer of poetry, short stories and scientific articles on various subjects. 
ISSN(Online) : 2456-8910

International Journal of Innovative Research in Applied Sciences and Engineering (IJIRASE) Volume 3, Issue 3, DOI: 10.29027/IJIRASE.v3.i3.2019, 466-470, September 2019

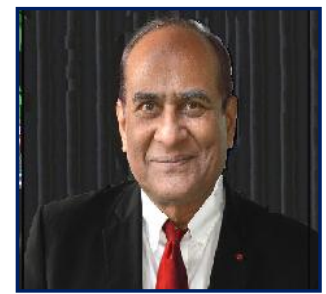

Third Author H. N. Dutta is working as an Adviser (R\&D) to Silver Line Prestige School, Ghaziabad. He retired from the National Physical Laboratory, New Delhi as Scientist-G in the year 2007 and led Roorkee Engineering \& Management Technology Institute as the founder director. He did his Ph D in 1975 from Kurukshetra University and has designed and developed various types of acoustic radars for India and Antarctica. He led CSIR Antarctic Program as the Convener and he himself has been thrice to Antarctica as part of the Indian Scientific Expeditions to Antarctica. Dr Dutta has guided $9 \mathrm{Ph} \mathrm{D}$ theses on Antarctic environment. He holds an international patent (World Intellectual Property Organization) on the use of acoustic radar technology in detecting precursor of an earthquake. Dr Dutta is the Top Writer 2018 on Quora.com where he has written 925 answers related to Antarctica, earthquake and environment; these answers have $487 \mathrm{k}$ views. He has been honored by many national / international bodies.

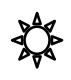

